\title{
Organizational Change and Relation between Employees in Kosova Banks
}

\author{
Justina Sh Pula \\ University of Pristina Economic Faculty \\ justina.pula@uni-pr.edu \\ Emin Neziraj \\ University Haxhi Zeka Peja Bussines Faculty \\ emin.neziraj@unhz.eu \\ Driton Sylqa
}

University Haxhi Zeka Peja Bussines Faculty

\section{Doi:10.5901/ajis.2015.v4n2s1p123}

\begin{abstract}
In this paper work we will deal with topics which are closely connected to understanding of phenomena, organizational changes regarding to how the change production process can makes resistance between employees. According to resistance We will try to find the difference between employee's and managers behavior in different banks such are Sweden and Kosovo. The companie which we used for the case study are Commercial bank in Kosova.
\end{abstract}

Keywords: Organizational change, dealing, management, banks

\section{Problem Discussion}

Hence, organization change can be viewed as revolutionary or evolutionary; transformational or transactional; planned or unplanned; and so on. Irrespective of the nature of the change, John Kotter (1996) in (Burke, 2011:3) So organizational change is more and more important for organizations in order to adapt to environment and stay competitive. The applying organizational change in organization is a "managing systematic process for applying behavioral science principles and practices in organizations to increase individual and organizational effectiveness" (French and Bell, .1999:24). However, various authors such as Kotter and Schlesinger, Hardy, Hoffman, Myth 0 and. Mousetrap, De Pree, identifies the problems about how to apply the change program in organization. The problem is resistance of employees for changes.

So according to (Kotter \& Schlesinger, 1979:107), "one of major reason why people resist organizational change is that they think they will lose something of value as a result in these cases, because people focus on their own best interests and not on those of the total organization, resistance often results in 'politics' or 'political behavior". Also, in article was make a study as how the change organizational processes can affect change in the thinking of members in the organization, where she put the claim that the members of organization must have logical strategic thinking, this thinking can make much easy the production change process in organization. But her main concern was the impact ambles of individuals to implement the strategic action.

From last sentence we can agree with study of Hoffman, who was explain that the problem in organizational development process can be people reaction and relation between employees when happen the change planed process.

However, "the key elements in the art of working together are how to deal with change, how to deal with conflict, and how to reach our potential ...the needs of the team are best met when we meet the needs of individual persons" (http://www.bayt.com/en/employer-article-6541/). According to last sentences or with theoretical approach by De Peer (http://www.iculturelink.com/consulting/teamwork/), I can consult that the problem how to deal with conflict between organizational members passes through four stages so regarding with, there is a different four stages where people are turn. 


\subsection{Problem formulation}

The aggregation of the above issues results in the following research problem. How change process can affect into relation between organizational members from different companies which are from different courtiers and how to deal with this?

\subsection{Purpose}

Our purpose is to investigate the change process which is caused by new production and how this kind of change process can disrupt relationships between employees in banks. The focus of this master thesis it will be explanation how the change process can make the problems into relation between employees caused by resistance in banks.

The analyses about which elements of resistance are similar or different in three banks can contribute in understanding how the resistance of employees is present in different banks. The explanation of this process it will be present according to relevant literature and other relevant sources which are useful in this study. Focus of this study is management change caused by new production process, but the main concern it will be how the management change can make the resistance between employees.

According to case study the concern it will be to compare the resistances in both companies, because in those three banks came to the organizational changes. What is same in these change process is that both companies the change process are focus in the production process. So the members of those companies have the quite similarly problem which is resistance to change process.

\section{Theoretical Background}

\subsection{Organizational development process}

The organizational development presents the set of changes which are occur in organization. The changes include the acceptance and development of new ideas, forms and organizational human behavior. So organization in the modern economy is characterized by continuous change. Changes have their own tempo and dynamics. These include the process of changing in existing organization and their components. The value of the company is reflected on an ability to change.

Organizational change refers to how profit and non-profit organizations planed, to introduce and manage changes. Changes can be caused by interior side or external factors. Inline factors relating to the employees of the organization, a foreign the activities of competitors, shareholders, legal bodies, natural phenomena and the general economic conditions. So, generally speaking, organizational change process can be defined as a process of transition (transition) from the old, inappropriate organizational solutions, under the new solution, compatible with the requirements of the business environment (S. Martinovic, 2004;34).

"Managers can focus four types of change within organizations to achieve strategic advantage. These four types of changes are": Technology change, production and services change. Strategy and services change and culture change (R.Daft, 2013:433).

Every type of organizational change development uses the total system perspective. Total system focuses on changes in organizational processes, structure and the culture change.

Organizational processes are the way how things get done in the organization. With other words the organizational processes is "techniques" for arriving to positive results. The positive results are when the organizational processes improve effectiveness.

Some important processes in an organization are: decision making, resource allocation, human resource practices and strategic management (French and Bell, 1999:4).

Organizational structure. Represent the dominant changes in the company. Organizational structure changes are including in whole organization. Changes in structure are a consequence of growth and development, and organizational factors. The scope and depth of change depends upon whether it is a reorganization or organizational transformation. Reorganization - changes whose goal is to customize the organization changes and the demands of the environment. Transformation - a radical change in structure, organizational culture, attitudes, values employees. In contemporary 
practice, the most common reasons for changes are: mergers, acquisitions, changes in top management and others .

According to (French and Bell, 1999) organizational structure change is the design of the organization; it is about how the parts are connected with each other. Important in this case is how individual work tasks are designed, and how they are integrated in the whole organization. "Organizational culture represents the shared values, assumptions and beliefs by organizational members, which shape how they perceive, think and act. Important to mention here is the fact that the culture is always company-specific. There cannot be another company who shares exactly the same culture" (http://www.au.af.mil/au/awc/awcgate/ndu/strat-ldr-dm/pt4ch16.html).

When creating a 'new organizational culture', it is important to use values that are: humanistic, optimistic and democratic. Democratic is about the need that makes it possible that everybody can participate (French and Bell, 1999:62).

Culture creates the leaders .Culture formed during critical events. Culture developed to primarily men maintain by employees. There are internal and external adaptations of culture. Internal adaptation is happening in the companies, and external outside companies. External has all the elements of-vision, the strategy of how to destroy us. Internal has some of the group, teams with the same vision in order to achieve the goal of the first man. The most important thing is to maintain organizational culture. Organizational is that the managers need to pay attention. Always should mold, fix, correct culture. Both the leader and the members should work together to modify their interactions to become more mutually effective toward organizational goals (French and Bell, 1999:68). For the implementation of Total System organization is in need to respect contemporary trends of change management process.

There are five identification of contemporary trends in change management process or (from) organizational development: a) Increasing of task forces implementation process of the new work, b). Attention to developing change process theory, c). Expanding interest in managing conflict, d). Advancing sophistication in organizational change resulting research, and e). The intensive focus on designing organizational culture as means of how to managing the organizational change process (Carter McNamara (2013:3). I can see that the elements such as increasing of task forces of new work, expanding interest in managing conflict and part of how to managing the organizational change process, can be a good basis of interior theoretical study in business environment during the emergence of organizational change or organizational development (http://managementhelp.org/organizationalchange/\#anchor574384). As we can be seen in these elements of themselves have much lateral connection between themselves and the lateral connection for which I care it is about the human factor and human behavior in organizational change process.

\subsection{Resistance to change}

For instance, the demand for change can come from external and/or internal forces. In case there occur 'people problems' or 'work-system problems' within the organization, it can trigger the need to change into a better working environment. The change in business environment can come from internal and external side. So component of human stress caused on the basic of organizational change is external effects from market environment.

(http://webcache.googleusercontent.com/search?q=cache:2jXmDKa9WXQJ:highered.mheducation.com/sites/dl/fre e/0073404993/579428/Sample_Chapter.pdf+\&cd=3\&hl=en\&ct=clnk).

In this theoretical study of organizational change process the focus will be given to internal side, because this is the one of main subject of this fieldwork which can study more deep the human reaction of change development process.

The organizational change takes humanistic behavioral science knowledge it is for it because the target of change may be the organizations a whole and the specific part of it, or even particular individual . Included that one of the problems arising in the organizational changes is itself human resource -the human resource according to some polls $20 \%$ can affect the flow in organizational changes (S. Martinovic, 2004:37). Before I begin with considering the possible consequences of organizational change into resistance it is important to determine what actually causes resistance and who does it do. According to Kotter and Schlesinger (1979) the main form of diagnosing resistance, is actually who can make the resistance and the resistance can make human forces.

The change process always causes conflicts between their actors. Any change process has own provision of employees resistance. The implementation of organizational changes will result not only resistance but also stressful situations.

Situation after beginning of change process in company is mostly unknown and causes the insecurity climate.

The problems with which organizations can meet on organizational change from resistance side are (http://www. torbenrick.eu/blog/change-management/change-is-not-the-problem-resistance-to-change-is-the-problem/):

- Counteraction and resistance to any change, it is "unknown" 
- Fear of loss of personal position, power and influence

- Attitudes and opinions to the existing way of better and it should not be changed

The greatest resistance causes by change process are related to people. This is one of the most important tasks of management in overall how to manage organizational changes.

So the change process bring the human resistance has one of main problems in organizational development. And if it is possible that organizational change give us the positive and rational involve again can bring the negative consequences into group there are the big number of different reasons why is like this. Too many individuals can react very differently to change this can be one of elements why the positive change can bring negative consequences. To be clearer every individuals has his rational subjective thinking.

But why is like this, because people when happen total organizational change they thinking that they can lose something of value this can be one of major reason why people resist.

We can find in words of last sentence that people look they own best interest, their focus in organizational change is to find best self internets and get as many coaxing of causes of organizational change, this can change the behavior of workers and whole organizations.

Another possibility where people also resist in change process is when they does not understand the implication and perceive of organizational change. They think that the implication can cost them too much. Its coming question why they fear or on basic which orders they feel fear. So who gives the order the order give a manager, he used his power. So according to Jackson and Carter (2007) the organizational context power is the ability to get someone to do something that they do not particularly want to do. It is obvious that people who work in the organization always wanted to do what they do it then it could be if the river is to provide managers can disappeared.

So in this reason is present the word or concept "Power" bass is the reason, because it comes from not understanding some one who want to make the changes in organization or a new vision in business or organization.

Means one of vision on the basis that people resist change is of misunderstanding which are caused by the managing own power. As we are known the manager has the property rights and authority that a business directive which is in the service of all it is if there are objective, then workers would not be that resists. According to Jackson and Carter (2007) the property rights of power is value of stems from the belief that if someone owns something, then, providing that they do not damage the rights of other people, they are free to do what they like their property.

When managers initiate on change they must have relevant information requires conducting adequate organization analyses. Relevant information which he must have and can take employees from the employees information can be differently interpret from managers and aspects that bring the low resistance.

According relevant information by employees and understanding differently by managers can be explained through the react of truth. Regime of truth Jackson and Carter (2007), is of property rights of power which the managers can use, so if the managers do use the regime to judge the relevant information then in change situation common the high resistance. In one another theoretical approach the power can provide the energy for change process. According to the last sentence can power the mechanism with which we can make good strategic change and if it is like this that have positive meaning of resistance. The positive resistance is when the employees follow the instruction with they own contribute.

\subsection{Dealing with resistance and their stages.}

For instance, the demand for change can come from external and/or internal forces. In case there occur 'people problems' or 'work-system problems' within the organization, it can trigger the need to change into a better working environment. The change in business environment can come from internal and external side. So component of human stress caused on the basic of organizational change is external effects from market environment. (http://webcache. googleusercontent.com/search?q=cache:2jXmDKa9WXQJ: highered.mheducation.com/sites/dl/free/0073404993/579428 /Sample_Chapter.pdf+\&cd=6\&hl=en\&ct=clnk).

In this theoretical study of organizational change process the focus will be given to internal side, because this is the one of main subject of this fieldwork which can study more deep the human reaction of change development process.

The organizational change takes humanistic behavioral science knowledge it is for it because the target of change may be the organizations a whole and the specific part of it, or even particular individual (Meyerson \& Martin .1987).

Included that one of the problems arising in the organizational changes is itself human resource -the human resource according to some polls $20 \%$ can affect the flow in organizational changes (Martinovic, 2004). Before I begin with considering the possible consequences of organizational change into resistance it is important to determine what 
actually causes resistance and who does it do. According to Kotter and Schlesinger (1979) the main form of diagnosing resistance, is actually who can make the resistance and the resistance can make human forces.

The change process always causes conflicts between their actors. Any change process has own provision of employees resistance. The implementation of organizational changes will result not only resistance but also stressful situations.

Situation after beginning of change process in company is mostly unknown and causes the insecurity climate.

The problems with which organizations can meet on organizational change from resistance side are (http://www. bovey.com.au/files/rcap.pdf pg 374) :

- Counteraction and resistance to any change, it is "unknown"

- Fear of loss of personal position, power and influence

- Attitudes and opinions to the existing way of better and it should not be changed

The greatest resistance causes by change process are related to people. This is one of the most important tasks of management in overall how to manage organizational changes.

So the change process bring the human resistance has one of main problems in organizational development. And if it is possible that organizational change give us the positive and rational involve again can bring the negative consequences into group there are the big number of different reasons why is like this. Too many individuals can react very differently to change this can be one of elements why the positive change can bring negative consequences. To be clearer every individuals has his rational subjective thinking.

But why is like this, because people when happen total organizational change they thinking that they can lose something of value this can be one of major reason why people resist .

We can find in words of last sentence that people look they own best interest, their focus in organizational change is to find best self internets and get as many coaxing of causes of organizational change, this can change the behavior of workers and whole organizations.

Another possibility where people also resist in change process is when they does not understand the implication and perceive of organizational change. They think that the implication can cost them too much. Its coming question why they fear or on basic which orders they feel fear. So who gives the order the order give a manager, he used his power. So according to Jackson, \& Carter (2007) the organizational context power is the ability to get someone to do something that they do not particularly want to do. It is obvious that people who work in the organization always wanted to do what they do it then it could be if the river is to provide managers can disappeared.

So in this reason is present the word or concept "Power" bass is the reason, because it comes from not understanding some one who want to make the changes in organization or a new vision in business or organization.

Means one of vision on the basis that people resist change is of misunderstanding which are caused by the managing own power. As we are known the manager has the property rights and authority that a business directive which is in the service of all it is if there are objective, then workers would not be that resists. According to Jackson, \& Carter (2007) the property rights of power is value of stems from the belief that if someone owns something, then, providing that they do not damage the rights of other people, they are free to do what they like their property.

However, in can happen that the organization of a low level of trust between employees and managers and it is consequently of misunderstandings to develop change. If happen these sudden situation then genesis problems I was again self interest of employee in change process.

The different, actor easements of change in process can give another reason why people resist organizational change, because the people assess the situations differently from their mangers change process.

When managers initiate on change they must have relevant information requires conducting adequate organization analyses. Relevant information which he must have and can take employees from the employees information can be differently interpret from managers and aspects that bring the low resistance.

According relevant information by employees and understanding differently by managers can be explained through the react of truth. Regime of truth Jackson, N. \& Carter, P. (2007), is of property rights of power which the managers can use, so if the managers do use the regime to judge the relevant information then in change situation common the high resistance. In one another theoretical approach the power can provide the energy for change process. According to the last sentence can power the mechanism with which we can make good strategic change and if it is like this that have positive meaning of resistance. The positive resistance is when the employees follow the instruction with they own contribute. 


\section{Empirical Findings}

Currently, Kosovo the unemployed force and they who are looking for a job. Around $42 \%$ of the population live under extreme poverty with less than 1.5 \$ per capita RIINVEST 2008:24). However, people employed in banks, have higher salaries than the majority of the employees in other industries.

Bank employees enjoy very good standards and good salaries if they are compared to other employees in Kosovo. However, there is a great difference between the annual income for a bank employee in Kosovo and any other developed country.

\subsection{Q1: Gender}

Table 1: Gender structure of responses

\begin{tabular}{|c|c|c|}
\hline & Number of responses & Percent \\
\hline Male & 99 & 61.88 \\
\hline Female & 60 & 37.00 \\
\hline Out base & 1 & 0.63 \\
\hline Total & 160 & 100 \\
\hline
\end{tabular}

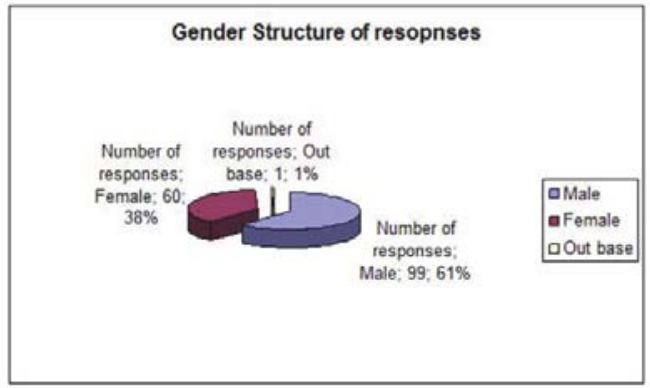

Figure 1: Gender structures of responses

In Kosovo female are less numerous to work in Bank.

\subsection{Q2: Age of employees}

Table 3: Age structure of employee

\begin{tabular}{|c|c|c|}
\hline & No. of responeses & $\%$ \\
\hline $26-35$ age. & 37 & $23,13 \%$ \\
\hline $36-45$ age. & 58 & $36,25 \%$ \\
\hline $46-55$ age. & 45 & $26,80 \%$ \\
\hline $56-65$ age. & 2 & $3,20 \%$ \\
\hline Out date-base & 18 & $10,62 \%$ \\
\hline Ukupno & 160 & $100 \%$ \\
\hline
\end{tabular}

According to Statistical Office ofKosovo, Kosovo has a very young population, where more than $55 \%$ of the population is below 28 years old. Hence, we have a greater number of employees in the Banks. 


\subsection{Q3: Level of education}

Table 2: Level of education

\begin{tabular}{|c|c|c|}
\hline & No. of responses & $\%$ \\
\hline Low Secundary School & 11 & $6,88 \%$ \\
\hline High Secundary School & 13 & $8,13 \%$ \\
\hline College & 32 & $20,00 \%$ \\
\hline Bechelor & 94 & $58,72 \%$ \\
\hline Bechelor specializtion & 1 & $0,63 \%$ \\
\hline Master & 7 & $4,38 \%$ \\
\hline PhD & 1 & $0,63 \%$ \\
\hline Out date -base & 1 & $0,63 \%$ \\
\hline Total & 160 & $100,00 \%$ \\
\hline
\end{tabular}

Banks, gather mainly high level employees On the other hand, employees in Kosovo Banks explain that most of the employees have a bachelor degree, in the second place other levels of education, then are employees with master level, and there are no people without diplomas.

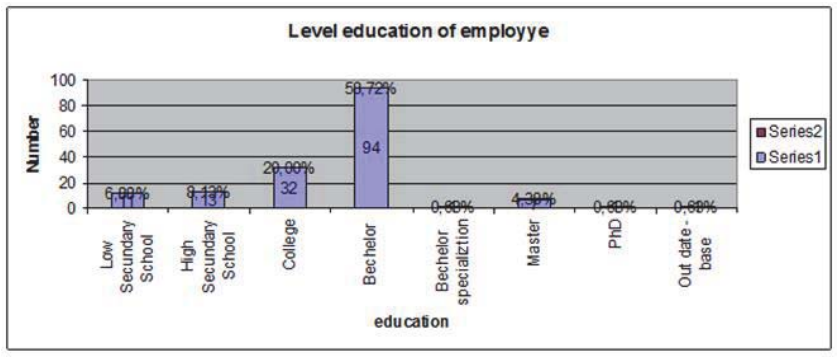

Figure 2: Level education of employee

\subsection{Q6. What is your position?}

Table 3: Position of employee

\begin{tabular}{|c|c|c|}
\hline & No of responses & $\%$ \\
\hline Top Manager & 13 & $3,75 \%$ \\
\hline Middle Manager & 73 & $8,23 \%$ \\
\hline Manager & 37 & $13,75 \%$ \\
\hline Sector Manager & 22 & $23,13 \%$ \\
\hline Service manager & 6 & $45,63 \%$ \\
\hline Out date-base & 9 & $5,51 \%$ \\
\hline Total & 160 & $100,00 \%$ \\
\hline
\end{tabular}

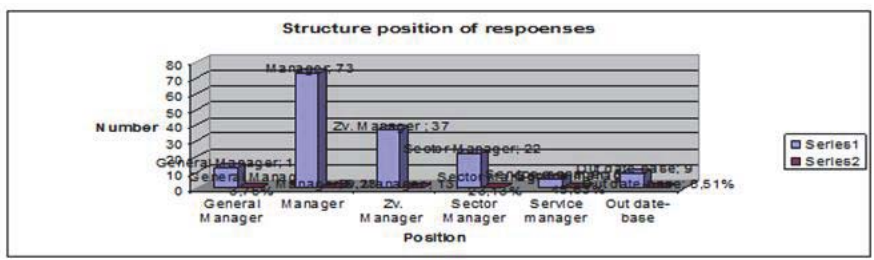

Figure 3: Structure positions of responses 
Most of responses come from peoples who work in banks; it is logical because banks employed more people.

\subsection{Q4. In what kind of department are you working?}

Table 4: Work sector employees

\begin{tabular}{|c|c|c|}
\hline & Number of responses & $\%$ \\
\hline Admin sector & 65 & 40.63 \\
\hline Service sector & 95 & 59.38 \\
\hline Total & 160 & 100.00 \\
\hline
\end{tabular}

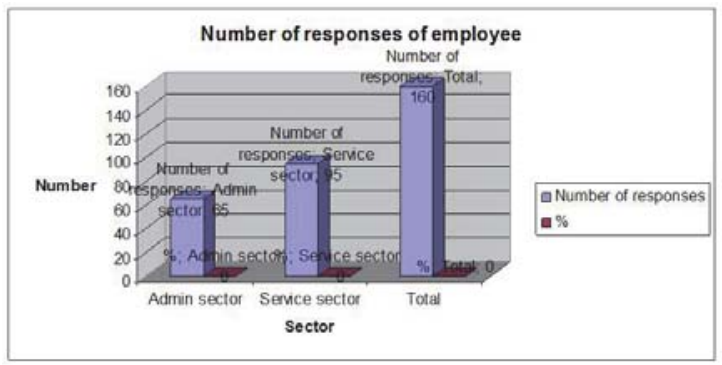

Figure 4: Work sector employees

\subsection{Q20 - 25}

Table 5: Indetification which kind of training of employee can influence in change bank efficiency in Procredit bank- Peja

\begin{tabular}{|c|c|c|}
\hline No & Training needs & Percent \\
\hline 1 & Negotiation & 50.00 \\
\hline 2 & Quality of service & 16.67 \\
\hline 3 & Innovation & 16.67 \\
\hline 4 & Management & 16.67 \\
\hline
\end{tabular}

In Procredit bank the employee seen that must of training needs it is about negotiation. And according to P.Ducker I can constant that the productivity of one business in this case Procredit bank is Negotiation. The negotiation in the bank must be perfect and that can depends of clients.

Table 6: Indetification which kind of training can influence in change bank efficiency in Privat Business Bank-Peja

\begin{tabular}{|c|c|c|}
\hline No & Training needs & Percent \\
\hline 1 & Negotiation & $16.68 \%$ \\
\hline 2 & Quality of service & $33.32 \%$ \\
\hline 3 & Innovation & $33.32 \%$ \\
\hline 4 & Management & $16.68 \%$ \\
\hline
\end{tabular}

The employee in this bank is see that the quality of service and innovation are major part of bank efficiency and they also have a needs in the training program to some seminar or training about how to make best service include some kind of innovation that maybe can be system of payment or online payment. The quality of a service is perceived by a costumer when the service is being purchased. The moment when the seller meets with the costumer is according to Grönroos called the moment of truth. The quality perceived by the consumer is not only created in the factory or at the moment of truth, it's build up by the whole bank. 
Table 7: Indetification which kind of training can influence in change bank efficiency in TEB Trade Enterprise Bank-Peja

\begin{tabular}{|c|c|c|}
\hline No & Training needs & Percent \\
\hline 1 & Negotiation & $33.33 \%$ \\
\hline 2 & Quality of service & $33.33 \%$ \\
\hline 3 & Innovation & $0.00 \%$ \\
\hline 4 & Management & $33.33 \%$ \\
\hline
\end{tabular}

Quality improvement is a dynamic process not only a single specific approach, therefore the work will continue after an installation or a change in the offer to the costumer. (Grönroos, 2000)

Quality should match the company's strategy and customer expectations and the service . It is commonly accepted that customers should get a bit more than expected out of the process. However, care must be taken for a persistent increase in quality offering may lead to increased expectations to the point of not being realistically sustainable. Similarly, negative experiences also tend to affect tolerance zones.

Table 8: Indetification which kind of training can influence in change bank efficiency in NLB New Lublan Bank-Peja

\begin{tabular}{|c|c|c|}
\hline No & Training needs & Percent \\
\hline 1 & Negotiation & 16.67 \\
\hline 2 & Quality of service & $33.33 \%$ \\
\hline 3 & Innovation & $25 \%$ \\
\hline 4 & Management & $25 \%$ \\
\hline
\end{tabular}

Table 9: Indetification which kind of training can influence in change bank efficiency in total of research analize

\begin{tabular}{|c|c|c|}
\hline No & Training needs & Percent \\
\hline 1 & Negotiation & $26.77 \%$ \\
\hline 2 & Quality of service & $33.33 \%$ \\
\hline 3 & Innovation & $23.33 \%$ \\
\hline 4 & Management & $16.77 \%$ \\
\hline
\end{tabular}

And if the way to the title was exhaustive and enigmatic, however, we get an instruction that Umberto Eco wrote in "One way that always turns out longer for reasons of beauty that is during the journey" (U. Eco STSH.. PD 1982:23). After that we came for detailed data processing, according to information based on the order of analysis of data for all banks.

In recent times, we are increasing the importance of analyzing the monitoring and education of employees in the skills and knowledge necessary for more efficient mode. For this reason many companies are implementing continuous training, which significantly increases the satisfaction of workers and thus their performance. Training of personnel, combined with appropriate changes in attitudes, increase the self-company staff, increasing their association with the organization and improving their knowledge and skills. Also, provides mutual division of knowledge and experience helps professional levels and achieve high levels of organizational culture.

\section{Analysis and Interpretation}

\subsection{Training change development process}

The particular findings regarding generally answers of question 1 (Appendix B) and as well as $\mathrm{H} 1$, in the Banks is offer the training development program relevancy to daily work. According to those findings, I can agree with theoretical approach because the offer training development process in banks should consist of "planed programs which is designed to improve performance at the individual, group which should be adapted to daily work "(Cascio, W., 1998:262). This can give me a right in saying that the banks, which offer training development program with the main component daily work activities in organization, can make organization more successful or in other words, the organization more efficient.

According to question 2 (Appendix B), and in general to the answers of responds of on this question, I have noted that the management Bank staff gave to the majority of employees access to relevant training programs and due to this fact the banks have increased its efficiency. According to Latham and Crandall (2001) have pointed out that, over the 
past decade the training literature has emphasized that access of employees to relevant training development process should be linked to an organization's strategy as a part of investment in people, because those investments in people mean the higher profit for organization. Connection between theoretical and practical approach improve the supporting of practical findings to theoretical approach about access to training development.

According to question 9 (Appendix B), I can conclude that the training development program which is offered by management staff for their employees influence in daily work activities that can confirm the $\mathrm{H} 1$ that the training development program influence in Banks efficiency from human resource perspective.

So according to (Ulrich, D., \& Wayne B, 2005 to improve and make better the performance and knowledge skills of employees' managers should focus in education program which should give the answer about how in particularly way the employees can easy influence in daily work activities and those education programs adopt to daily activities. Here, I have the similarity with theory which gave the right again to establish the $\mathrm{H} 1$ of this thesis.

According to, responsibility of choosing adequate training development program types which should influence in bank efficiency and regarding to question where I was found the compatibility with daily work activities and training. The managers of those banks are found the best way of training development program type evaluation. I can constant now that the connection between practically and theoretical approach regarding with managers responsibilities of choosing the training development program type.

\subsection{Performance caused by training change development program}

The employees of "NLB" bank seen that the performance caused by training development process of quality service increase the success in bank, they also have needs in the training development program for some seminars or trainings about how to make best service. So, according to Grönroos (2000) the training development program of quality service include the performing of ways to clients and costumer perceived of service after training development process can increase the profit of organization.

According to Damanpour and Aravind (J.Hage and M Meeus, 2006) the performance caused by innovation training development process in organization stimulate the growth and productivity not just in those organizations but also can develop other organization which are adopt to use them. It is very important for one organization to develop new ideas of making the product and services, because the new product or services for organizations can bring better position in market. With other words, if company creates a new product automatically gives other companies a positive infusion, because first of all, this new product could facilitate to the other companies for work or even for create a new idea of this innovative product or service. According to this the employees of "NLB" bank and "TEB" are signified that the performance caused by training development program of innovation as the main factor which can influence in bank efficiency and their professional development.

\subsection{Satisfaction caused be training change development process}

According to questions 5, 6 and 7 (Appendix B), we found out that the satisfaction caused by training development program is positive. Which means that workers in the banks are happy with training program, therefore, they are more productive in daily work activities. The satisfaction of employees is one of main component for successful daily work. Regarding to Petter, if in an organization is a high level of satisfaction, there will be no problem for future development of company. Through practical findings and theoretical approach, I conclude that the training and development process performance caused by training development process influence in bank efficiency

\section{Conclusion}

Since some years Kosovo Bank, are facing difficulties in many fields. Problems are found mostly in administrative sectors, encountering the lack of knowledge and experience. The main challenge is how to strengthen human the capacity and to identify what do employees need to be more efficient and qualified for daily activity performance.

The conclusion of this thesis work comes down to answer of Hypothesis 1, which in itself are still the elements of training development process and performance caused by training development program and both phenomenon's influence in efficiency on Kosovo Banks .

So regarding with particularly findings and similarities with theory I can conclude that the specific topics of training process can develop the human performance which can influence in bank efficiency. So one main topics of training 
program which influence in bank efficiency are training of negotiation performance, quality of service performance, flexible management performance and innovation performance. Those elements are really necessary for bank efficiency from human perspective. Also the training development process should give answers to daily work activities, because after those training the employees would be able to increase their job performance. Thus, they can build high human productivity in organization.

Since of modern aspect of economic activities today's in the world the human productivity is one of major resource which must be develop continually in the future. Like Kosovo banks and the European banks should involve the training program which should increase the productivity the meaning of this is that human resource is main of part for establishment for organization. So the training development program should be continues process to answer the market needs, also thus training programs should give a answer to clients needs in the future. So I can finally conclude that the training development program can influence in productivity on Kosovo banks and also the training program can increase the human productivity regarding with daily work activities.

Finally, we hope that we have given a modest contribution with this paper and we have the road for another scientific researches work regarding this issue. This bachelor thesis focuses in Kosovo Bank and it could be useful for those, who are dealing with economic activities in this region and further scientific research. In addition, it can be useful for those who deal with the problem training development process of human resource

\section{References}

Beck, R., 1987. Visions, Values, and Strategies: Changing Attitudes and Culture.Academy of Management Executive, 1(1): 33-41.

Hardy, C., 1996. Understanding power: Bringing about strategic change.British Journal of Management 7, (special issue March): p3-16. Kotter, J., 1996. Leading change. Boston: Harvard Business School Press. 33-41.

Kroenke, D., \& Hatch, R., 1994. Management Information Systems, 3rd Ed. CA: Mitchell Mc Graw-Hill. 75-81.

Yin, R., 2002. Case Study Research Design and Method. London: Sage Publications, Inc. 18-23.

Yukl, Gary, 2006. Leadership in Organization. New Jersey: Prentice Hall.

Strebel, P., 1996. Why do employees resist change? Harvard Business Review 74 (3): p86-92. 